\title{
Oletatav paganlike eestlaste puust jumalakuju Oleviste raamatukogus
}

Urmas Sutrop

\begin{abstract}
Teesid
Eesti muistsetest (maa)jumalatest ja nende panteonist teame üpris vähe. Liivimaa kroonikast on meil teateid saarlaste suurest jumalast Taarapitast ja puust jumalakujudest. Kagu-Eesti viljakusele pühendatud jumala Peko kultusest on meil teateid hilisest ajast ning üks Peko kuju on säilinud.

Riias Läti akadeemilises raamatukogus säilitatakse Johann Christoph Brotze (1742-1823) kogus pilti aastast 1800, millel on Eduard Philipp Körberi (1770-1859) poolt kujutatud oletatavat paganlike eestlaste jumalakuju, mis asus Tallinna Oleviste kiriku raamatukogus. Sama kujuke on jäädvustatud ka 1875. aasta Eestimaa Provintsiaalmuuseumi kataloogis. Hilisemad teated kujust puuduvad.

Artiklis analüüsitakse kirjalikke teateid Oleviste raamatukogus hoitud eestlaste puust jumalakuju kohta alates Hupelist. Seejärel kirjeldatakse Brotze kollektsioonis olevat pilti ja Provintsiaalmuuseumi kataloogi joonist ning nende juurde kuuluvaid kommentaare.
\end{abstract}

Märksõnad: puust jumalakuju, eesti usund, Johann Christoph Brotze, Eduard Philipp Körber, Oleviste raamatukogu

Eesti muistsetest (maa)jumalatest ja nende panteonist teame üpris vähe. Liivimaa kroonikast on meil teateid saarlaste suurest jumalast Taarapitast (Sutrop 2002). Pihkva eestlaste Peko kultusest on meil seevastu teateid üpriski hilisest ajast. Seni oleme pidanud leppima sellega, et meil on materiaalsetest jumalakujudest ainult Kagu-Eesti viljakusele pühendatud jumala Peko kuju ning lisaks veel kaks koduhaldja Tõnni kujukest. Ainsat teadaolevat ehtsat Peko kuju hoitakse Tartus Eesti Rahva Muuseumis (Ränk 1934; Hagu 1975). Selle põhjal valmistatud koopiad on levinud eriti Setumaal.

Siinkirjutajal õnnestus leida pilt aastast 1800 , millel on kujutatud oletatavat paganlike eestlaste jumalakuju, mis asus Tallinna Oleviste kiriku raamatukogus. Eduard Philipp Körberi (1770-1859) kujutis või koopia sellest on praegu Riias Läti akadeemilises raamatukogus Johann Christoph Brotze (1742-1823) kogu "Sammlung verschiedener Liefländischer Monumente...." 8. osas.

Paganlike eestlaste oletatava jumalakuju pilti vaadates tekib arvukalt küsimusi. Kas kuju on ajahambast puutumata jäänud? Kui kuju pole hävinud, kus see võiks asuda? Kas kujust on säilinud teisi kirjalikke teateid? Oli see üldse eestlaste jumalakujuke?

http://haldjas.folklore.ee/tagused/nr27/sutrop.pdf 
Urmas Sutrop

Esimesele kahele küsimusele ei oska ma vastata. Oleviste kirik hävis tulekahjus ööl vastu 16. juunit 1820. aastal, mil kiriku torn süttis pikselöögist. Raamatud pääsesid imekombel tulekahjust, sest need olid raamatukogu remondi ajaks viidud käärkambri kõrvale võlvitud ruumi, mis jäi tulest puutumata (Robert 1979: 233). Oleviste kirikut ja raamatukogu käsitlevates kirjutistes ning uurimustes ei ole kujukest kahjuks mainitud (Hansen 1885; Neumann 1904; Robert 1979, 2002).

\section{Eestlaste puust jumalakuju mainimisi kirjanduses}

Vanim mulle teadaolev kirjapanek Oleviste raamatukogus olnud puust jumalakuju kohta pärineb August Wilhelm Hupelilt (17371819). Ta kirjutas, et Oleviste kirikus "hoitakse ühes eraldi ruumis õige iseäralikku, aga enamasti vanadest raamatutest koosnevat raamatukogu.... võõrastele näidatakse ka paari väikest tähelepanuväärsust, nagu üht puust nikerdatud vanade eestlaste ebajumalakuju [minu esiletõste-US], üht vana patukahetsuskirja, dr. Lutheri käega [kirjutatud] kirja ja muud sarnast" (Hupel 1774: 330). Hupeli loetletud vaatamisväärsusi tsiteeritakse ilma sisusse süvenemata siin ja seal. Näiteks Tallinna Oleviste raamatukogu 450. aastapäeva näituse kataloogis (August Wilhelm Hupel Oleviste raamatukogust 18. sajandi lõpul; Kõiv \& Luuk \& Reimo 2002: 173) või ajaloolises ülevaates Eesti esimestest vabamüürlastest (Hakman 2000: 6).

Oleviste raamatukogu läks 1842. aastal Eestimaa Kirjanduse Ühingu valdusesse. Aastail 1863-1864 võeti Oleviste raamatud arvele ning hajutati muude raamatute hulka. 1864. aastal asutati ka Eestimaa Provintsiaalmuuseum, mille kogud kuulusid Eestimaa Kirjanduse Ühingule. Ilmselt paigutati paganlike eestlaste jumalakuju raamatutest eraldi muuseumi, sest Gotthard v. Hansen (1821-1900) kirjeldab 1875. aastal puust ebajumalakuju provintsiaalmuuseumi kodumaiste muististe hulgas rubriigis "ebajumalateenimine ja kirik":

Oletatav eesti ebajumalakuju, mida varemalt hoiti Tallinnas Püha Oleviste kiriku käärkambris. Tahvel V. 22 [vt joonis 1]. See on kasepahast korralikult nikerdatud ning kujutab maha 
Joonis 1. Oletatav eestlaste jumalakuju Eestimaa Provintsiaalmuuseumi kataloogist (Hansen 1875).

kükitavat inimese keha pikkade taha langevate juuste, grimassis näo ja pikkade kõrvaehete, põimitud käte ja põlvedega; jalgade alumine osa on vormitu ja lõpeb viie teravikuga. Kogu [kuju] kõrgus on $90 \mathrm{~mm}$ (Hansen 1875: 72-73, tahvel V). ${ }^{1}$

Hans Treumann (1905-1974) viitab ühes oma artiklis nii Hupelile kui ka Hansenile ja kombineerib nende kahe peale kokku: "Omajagu tähelepanu väärib [Tallinna Oleviste] raamatukogu juures esitatud väike museaalne ekspositsioon ... maarjakasepuust voolitud eesti ebajumal ..." (Treumann 1970: 538-539; 1977: 58). ${ }^{2}$

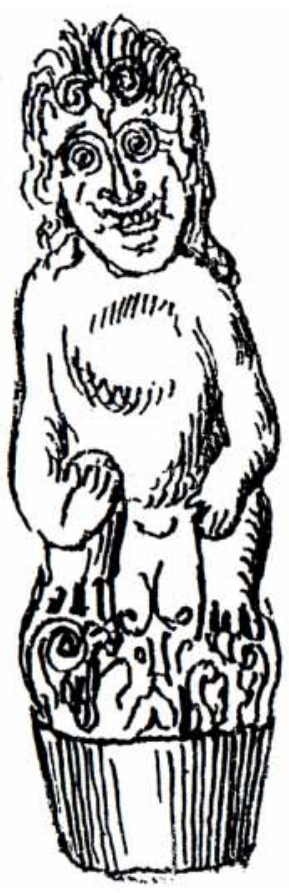

\section{Eestlaste puust jumalakuju kujutis Brotze kollektsioonis}

Nagu eestlaste puust jumalakuju mainimised kirjanduses, nii on ka Körberi ja Hanseni joonised jäänud meie rahvausundi uurijate tähelepanu alt kõrvale. Oletatavat eestlaste puujumalat (joonis 2) on ilmselt peljatud, sest Körber on pildil selle kohale paigutanud Pirita kloostri abtissi saua. ${ }^{3}$ Nii on kristlus paganlikest eestlastest üle ja valitsejakepiga saab vajadusel puujumalale lagipähe lajatada. Ehk hoitigi puukujukest seepärast kiriku võlvide all raamatukogus, et selle oletatavat väge nõrgestada või kaotada.

Pirita kloostri abtissile omistatud saua ja paganlike eestlaste jumalakujukese pildi juures on saksakeelne tekst:

Fig. 1. Der Stab der Aebtißin von St. Brigitten - den eine ${ }^{4}$ am Altar Blatt dieses Klosters - so im Schwarzen Haupter Hause zu Reval befindlich - abgemahlte Vorsteherin derselbe in der Hand trägt. 


\section{Urmas Sutrop}

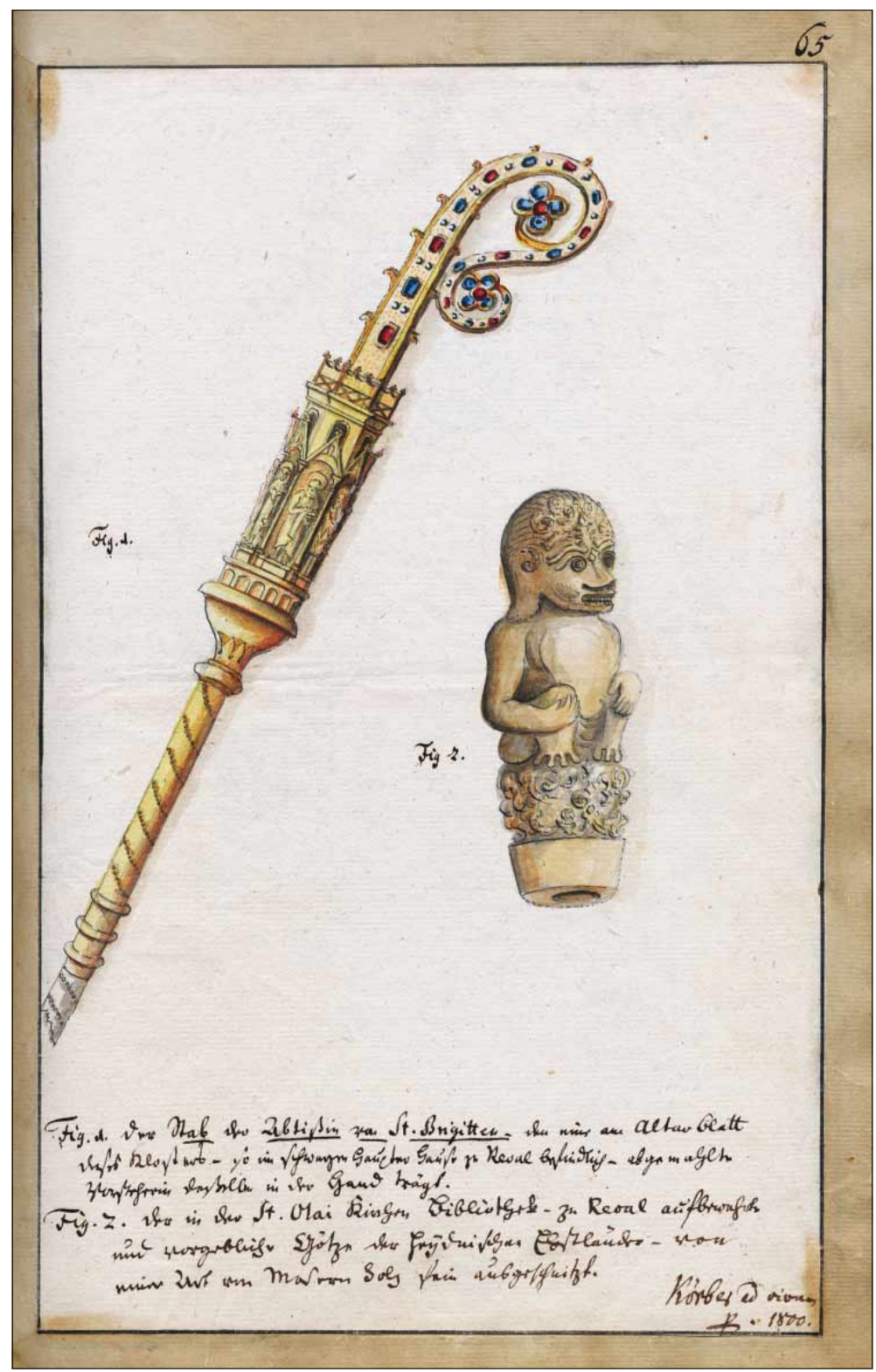

Joonis 2. Körberi joonistus (1800) oletatavast eestlaste jumalakujust, mille kohale on paigutatud kristlikku väge sümboliseeriv sau (Brotze kogu, Riia). 
Urmas Sutrop

Fig. 2. Der in der St. Olai Kirchen Bibliothek - zu Reval aufbewahrte und vorgebliche Götze der heydnischen Ehstländer von einer Art von Masern Holz fein ausgeschnitzt.

Körber ad vivum 1800

Kujutis 1. Püha Brigitta kloostri abtissi sau-mida üks selle kloostri altari tiival - mis asub Tallinna Mustpeade majas maalitud eestseisja käes kannab.

Kujutis 2. Oleviste kiriku raamatukogus-Tallinnas alal hoitud ja väidetav paganlike eestimaalaste ebajumal - ühest pahkliku puidu sordist peenelt nikerdatud.

Körber ad vivum 1800

Joonise 2 kujutisel 2 oleva paganlike eestlaste jumaluse kohta on Brotze kirjutanud lühikese kommentaari (joonis 3, selle lehekülje pöördel kirjeldab ta Mustpeade majas asuvat, legendi järgi Pirita kloostrile kuulunud altarit, millelt on pärit joonise 2 kujutis 1 - vt märkust 3):

Auch zeigt Fig 2 das auf der S. Olai Kirchen Bibliothek befindliche Götzenbild, so man für einen Götzen der alten heidnischen Ehsten hält. Es ist noch unerwiesen, ob die Ehsten Götzenbilder gehabt haben, auch verräth das Schnitzwerk dieses Stückes

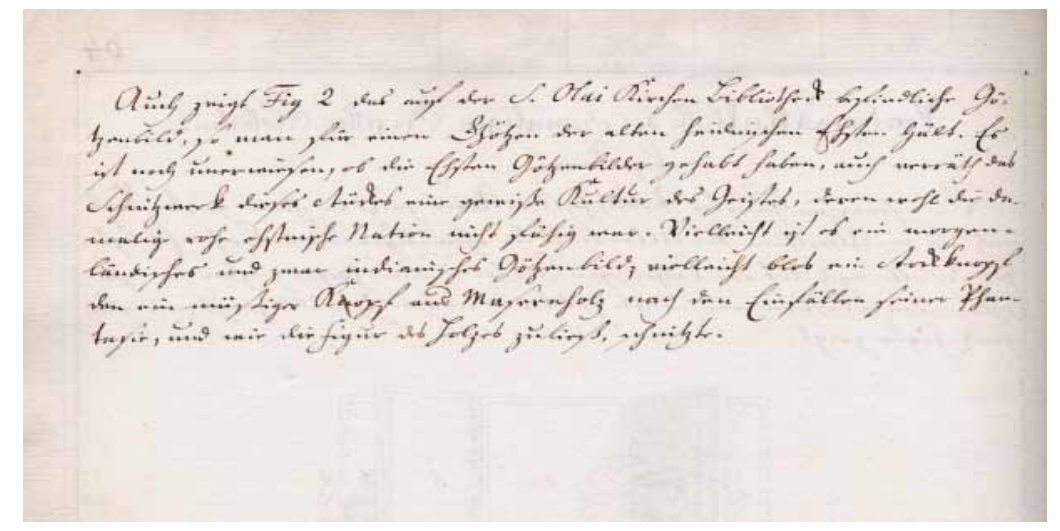

Joonis 3. Brotze kommentaar Körberi joonistatud jumalakuju kohta (Brotze kogu, Riia). 


\section{Urmas Sutrop}

eine gewiße Kultur des Geistes, deren wohl die damalige rohe ehstnische Nation nicht fähig war. Vielleicht ist es ein morgenländisches und zwar indianisches Götzenbild; vielleicht blos ein Stockknopf den ein müßiger Kropf $f^{5}$ aus Masernholz nach den Einfällen seiner Phantasie, und wie die Figur des Holzes zuließ, schnitzte.

Veel näitab kujutis 2 Oleviste kiriku raamatukogus leiduvat ebajumalakuju, mida peetakse vanade paganlike eestlaste ebajumalaks. See on veel tõestamata, kas eestlastel on olnud ebajumalakujusid, samuti reedab selle tüki nikerdustöö teatud vaimukultuuri, milleks tolleaegne toores eesti rahvas küll võimeline polnud. Võib-olla on see hommikumaine ja nimelt indiaanlaste ebajumalakuju; võib-olla ainult kepinupp, mille jõude mõistus pähe tulnud fantaasia järgi pahklikust puust, ja nagu puu[tüki] kuju võimaldas, nikerdas.

\section{Lõpetuseks}

Hansen kirjutab, et eestlaste ebajumal oli grimassis näoga või koguni karikatuurne, koledalõustaline (mit fratzenhaftem Gesicht). Kui me aga võrdleme seda Hanseni kujutist (joonis 1) Körberi omaga (joonis 2), siis näeme, et Hanseni kujutis ise on tervikuna karikatuurne. Samas on see grimassis nägu palju talupoeglikum, puust jumala nägu pole nii võõrapärane nagu varasemal Körberi kujutisel. Samas ei jaga Hansen Brotze kahtlusi (ilmselt polnud ta nendega tuttavgi) eestlaste võimes luua jumalakujusid.

Isegi kui Körberi poolt kujutatud nikerdustöö ei olnudki muistsete eestlaste puujumal, vaid kuulus hoopis teistele rahvastele või oligi kepinupp, on meie jaoks tähtis, et 18. ja 19. sajandil peeti seda kuju eestlaste omaks ja veidi kardeti. Ei tasuks tõsiselt võtta ka Brotze kommentaari, mille järgi muistsete eestlaste "toores" vaimukultuur jumalakujukeste loomist ei võimaldanud. Peko ja koduhaldja Tõnni kujude olemasolu on vastupidist juba tõestanud. Pealegi on teateid võimalikest Peko ja teiste jumalate kujudest rohkemgi.

Et jumalate materiaalsete kujude mõte siinkandis võoras polnud, tõestab ka koht Henriku Liivimaa kroonikast. Pärast piiskop Bertoldi tapmist lähevad saadikud Saksamaale uut karjast nõutama. Lahkuvad sakslased olid aga ühe puu oksale sisse lõiganud just nagu inimese pea. Liivlased pidasid seda sakside jumalaks ning arvasid, 
et sellest tuleb neile üleujutus ja taud. Kroonik jutustab, et liivlased keetnud kombekohaselt mõdu ja pidanud nõu. Seejärel võtsid liivlased pea puult maha, valmistasid kokkuseotud puutüvedest parve ja saatsid selle sakside jumala koos kristlaste usuga, mille nad enne endilt jõeveega maha pesid, merd mööda Ojamaale lahkujatele järele (Tarvel 1982: 33).

\section{Tänu}

Suur tänu härra Valdis Mazulisele ja Läti akadeemilisele raamatukogule sellest kogust pärit digitaalsete koopiate eest! Samuti tänan proua Mare Luuki TPÜ akadeemilisest raamatukogust, härra Heldur Niitu ja härra Jüri Kuuskemaad ning Eesti Teadusfondi (uurimistoetus nr 5292).

\section{Kommentaarid}

${ }^{1}$ Minu tõlge - US. Samas kirjeldab Hansen veel ühte oletatavat eestlaste kivist jumalakuju, mis oli leitud Lasnamäelt 1856. aastal. Kujust oli säilinud rind ja katkise näoga pea. Laius $55 \mathrm{~cm}$, kõrgus $71 \mathrm{~cm}$.

2 Treumann tõlgib Hanseni "es ist aus Birkenmasern" ilmselt Wiedemanni sõnaraamatule toetudes "maarjakasepuust".

3 Jüri Kuuskemaa juhtis (meilitsi 25.02.2004) minu tähelepanu vanade autorite eksimusele seoses "Pirita kloostri abtissi sauaga". Tegemist on puhtakujulise blufiga, mis sai alguse pärimusest, nagu oleks Mustpeade vennaskonna "Maarja altar" kunagi kuulunud Pirita kloostrile, kaevatud maa sisse ja hiljem ära "päästetud" Mustpeade majja. Seesinane altar on praeguseks tunnistatud anonüümse "Püha Lucia legendi" meistri tööks, mis toodi 1495 Lübecki kaudu laevaga Brüggest ja paigutati dominiiklaste Püha Katariina kirikusse. Sealt toodi altar pildirüüste eelõhtul 1524 Mustpeade majja. Nigulistes eksponeeritaval altaril on paremal sisetiival kujutatud abtissirüüs ja karjusesauaga püha Gertrudit Nivelles'ist, mitte püha Brigittat. Seega on maalil näha olev abtissisau anonüüm-abstraktne, mingi Brugges olnu järgi maalitud.

${ }^{4}$ Raskesti väljaloetav sõna. Seda võiks eine 'üks' asemel lugeda ka nur 'ainult' või nun 'nüüd'.

${ }^{5}$ Originaalis on algselt kirjutatud Knopf 'nupp' nii nagu paar sõna varem Stockknopf 'kepinupp'. Selles sõnas on $n$ läbi kriipsutatud, mille tulemusena sõna tuleb lugeda Kopf 'pea'. 


\section{Urmas Sutrop}

\section{Dokumendid}

Johana Kristofa Broces kolekcija "Sammlung verschiedener Liefländischer Monumente, Prospecte, Wapen etc etc zusammen getragen von Joh. Christoph Brotze. Achter Theil" Läti akadeemilises raamatukogus. Brotze kogu on kättesaadav ka internetis http://159.148.58.74/broce/, vt sealt 8. sējuma 1. daḷa.

\section{Kirjandus}

Hagu, Paul 1975. Setu viljakusejumal Peko. Keel ja Kirjandus 3, lk 166173.

Hakman, Johan G. 2000. Esimesed eesti vabamüürlased. Tartu: ASZ.

Hansen, Gotthard v. 1875. Die Sammlungen inländischer Alterthümer und anderer auf die baltischen Provinzen bezüglichen Gegenstände des Estländischen Provinzial-Museums. Reval: Lindfors' Erben.

Hansen, Gotthard v. 1885. Die Kirchen und ehemaligen Klöster Revals. 3. verm. Aufl. Reval: Franz Kluge. [Peatükk "Die Olaikirche", 2-24.]

Hupel, August Wilhelm 1774. Topographische Nachrichten von Lief- und Ehstland. Bd. 1. Riga: Johann Friedrich Hartknoch. [Faksiimile: Tallinn, 1992.]

Kõiv, Lea \& Mare Luuk \& Tiiu Reimo 2002. Näituse kataloog. Bibliotheca Revaliensis ad D. Olai. Tallinna Oleviste raamatukogu. Revaler Bibliothek zu St Olai. Tallinn, lk 123-184.

Neumann, Wilhelm 1904. Die Kirche zu St. Olaus. Eugen v. Nottbeck \& Wilhelm Neumann. Geschichte der Kunstdenkmäler der Stadt Reval. Bd. 2. Die Kunstdenkmäler der Stadt. Reval: Franz Kluge, lk 101-108.

Robert, Kyra 1979. Tallinna linna Oleviste raamatukogu ajaloost. Keel ja Kirjandus 4, lk 229-235.

Robert, Kyra 2002. Tallinna linna Oleviste raamatukogu ajaloost. Bibliotheca Revaliensis ad D. Olai. Tallinna Oleviste raamatukogu. Revaler Bibliothek zu St Olai. Tallinn, lk 26-38.

Ränk, Gustav 1934. Materiaalne Peko. Eesti Rahva Muuseumi aastaraamat IX-X, 1933/34. Tartu: Eesti Rahva Muuseum, lk 176-203.

Sutrop, Urmas 2002. Taarapita - saarlaste suur jumal. Mäetagused 16, lk 7-38.

Tarvel, Enn (toim) 1982. Henriku Liivimaa kroonika. Tõlkinud Richard Kleis. Tallinn: Eesti Raamat.

Treumann, Hans 1970. Adolph Simoni raamatute nimestik ja teisi raamatuloolisi mistselle. Keel ja Kirjandus 9, lk 528-542.

Treumann, Hans 1977. Vanemast raamatukultuuriloost. Tallinn: Eesti Raamat. 